\title{
Can facet joint block be a complementary or alternative therapeutic option for patients with osteoporotic vertebral fractures: a meta-analysis
}

\author{
Zhi Chen ${ }^{1}$, Chenyang Song ${ }^{1}$, Jianwen Chen ${ }^{2}$, Jun Sun ${ }^{3}$ and Wenge Liu ${ }^{1 *}(\mathbb{D}$
}

\begin{abstract}
Background: Recently facet joint block has been increasingly used to relief the residual pain after vertebral augmentation, but whether it can be a complementary or alternative to vertebral augmentation remain largely unknown. Thus, we conducted this meta-analysis to determine the effect of facet joint block in the treatment of osteoporotic vertebral compression fractures (OVCF).

Methods: Following PRISMA statement, a comprehensive literature search through Embase, PubMed, Web of Science, Wanfang Data, China National Knowledge Infrastructure and Chinese BioMedical Literature Database was performed to identify relevant studies. Studies comparing vertebral augmentation combined with facet joint block (combined therapy) with vertebral augmentation, and studies comparing facet joint block with vertebral augmentation were analyzed, respectively.

Results: A total of 10 studies were included. There were seven studies comparing combined therapy with vertebral augmentation, the results showed combined therapy was associated with significantly lower visual analog scale (VAS) scores on postoperative day 1,7, month 1, 3, and lower oswestry disability index (ODI) scores on postoperative day 1 , 7 , and month 3 . There were three studies comparing facet joint block with vertebral augmentation, the results demonstrated vertebral augmentation only provided better analgesia in month 1 after surgery, but it was associated with a higher incidence of refracture.
\end{abstract}

Conclusions: Current evidence suggested facet joint block might be considered as a complementary to vertebral augmentation in the treatment of OVCF, but it might not be effectively used as an alternative therapy.

Keywords: Facet joint block, Vertebroplasty, Kyphoplasty, Osteoporotic vertebral compression fracture, Meta-analysis

\section{Background}

With the aging population, the prevalence of OVCF is gradually increasing. Vertebral augmentation, including percutaneous vertebroplasty (PVP) and percutaneous kyphoplasty (PKP), was once considered as a highly

\footnotetext{
*Correspondence: Iwgspine@126.com

${ }^{1}$ Department of Orthopedics Surgery, Fujian Medical University Union Hospital, Fuzhou 350001, Fujian, China

Full list of author information is available at the end of the article
}

effective method in the treatment of OVCF. However, more recent studies demonstrated a significant number of patients suffered from residual pain and functional disability after surgery [1-3].

Currently, the underlying mechanism for the residual pain is yet to be established. Most of previous studies have focused on the fracture site, while the role of posterior elements is often disregarded $[4,5]$. Until recently, the importance of posterior supporting structures has 
been gradually elucidated. Doi et al. found that the collapse of vertebral body could lead to additional load and stress in the posterior elements [4]. Lehman et al. observed abnormal facet joint signal changes in patients with acute or subacute OVCF [6]. Furthermore, Park et al. demonstrated facet joint block could provide significant pain relief for patients with OVCF complaining of residual pain after vertebral augmentation, which supported the hypothesis that facet joint might be another source of pain [3].

In light of these findings, several studies have been conducted to investigate the efficacy of facet joint block as a complementary or an alternative to vertebral augmentation, but the results remain controversial [7-10]. Therefore, we conducted this meta-analysis to determine the effect of facet joint block in OVCF treatment.

\section{Methods}

\section{Search strategy}

This meta-analysis was registered on the PROSPERO (CRD42021262828) and conducted following the Preferred Reporting Items for Systematic Reviews and Meta-Analyses (PRISMA) statement (Additional file 1: The PRISMA checklist) [11]. After consensus has been reached, two researchers independently performed a comprehensive literature search through Embase, PubMed, Web of Science (WOS), Wanfang Data, China National Knowledge Infrastructure (CNKI) and Chinese BioMedical Literature Database (CBM) on June 18, 2021 to identify relevant studies. The following combinations of search terms were used in the systematic search: (vertebral fracture OR spinal fracture OR spine fracture) AND (vertebroplasty OR kyphoplasty OR PVP OR PKP) AND (facet joint block OR facet joint injection OR zygapophysial joint block OR zygapophysial joint injection OR zygapophyseal joint block OR zygapophyseal joint injection OR medial branch block OR nerve block). The search was restricted to clinical trials published in Chinese and English, and the references of all included studies were also reviewed for potential eligible studies.

\section{Inclusion/exclusion criteria}

Studies that met the following inclusion criteria were included: (1) Participants: patients with osteoporotic vertebral compression fractures; (2) Interventions: facet joint block combined with vertebral augmentation (combined therapy) or facet joint block alone; (3) Comparison: vertebral augmentation; (4) Outcomes: postoperative VAS scores, ODI scores and the incidence of refracture.

The exclusion criteria were as follows: (1) Secondary fractures caused by tumor, infection or bone metabolic diseases; (2) Studies comparing vertebral augmentation with other nerve block techniques (e.g., gray ramus communicans nerve block, nerve-root block or radiofrequency denervation); (3) Studies with insufficient data for calculating the results; (4) Conference abstracts, letters, case reports, reviews, duplicated studies and in vitro studies.

\section{Data extraction and quality assessment}

Based on the inclusion and exclusion criteria, two researchers independently screened the searched studies and extracted data from the eligible studies. Any discrepancy was resolved by consulting with a third author. For each included study, the following data were collected: first author, published year, country, study design, age, gender, sample size, type of surgery, anesthetic agent, VAS scores at postoperative day 1 and 7 , month $1,3,6$ and 12, ODI scores at postoperative day 1 and 7 , month $1,3,6$ and 12, the incidence of refracture and length of follow-up. The quality of each randomized controlled trial (RCT) and cohort study was evaluated using Jadad scale [12] and Newcastle-Ottawa Scale (NOS) [13], respectively. It was considered as a high-quality study, when the Jadad score was greater than 3 or NOS score was greater than 6 .

\section{Statistical analysis}

This meta-analysis was conducted using STATA 12.0 software. We calculated weighted mean difference (WMD) with 95\% confidence interval (CI) for continuous variables, and odds rations (OR) with 95\% CI for dichotomous variables. A 2 -sided $P<0.05$ was considered statistically significant. Heterogeneity was evaluated using the I-squared $\left(I^{2}\right)$ test. Heterogeneity of effects was identified when $I^{2}>50 \%$, and then the random effect model was applied and a sensitivity analysis was conducted. Otherwise, the fixed effect model was used.

\section{Results}

\section{Search results}

The flow chart of study selection processes is shown in Fig. 1. The initial search identified 204 relevant studies, and 132 studies were retained after removal of duplicates. Of these, 114 studies were eliminated after screening on titles and abstracts, another eight studies were excluded after full-text review. Finally, 10 eligible studies were included in this meta-analysis.

\section{Study characteristics and quality evaluation}

The characteristics of included studies are presented in Table 1 . There were seven studies comparing combined therapy with vertebral augmentation [7, 10, 14-18], and three studies comparing facet joint block with vertebral augmentation $[8,9,19]$. A total of 1145 patients were included, the mean age ranged from 62.59 to 


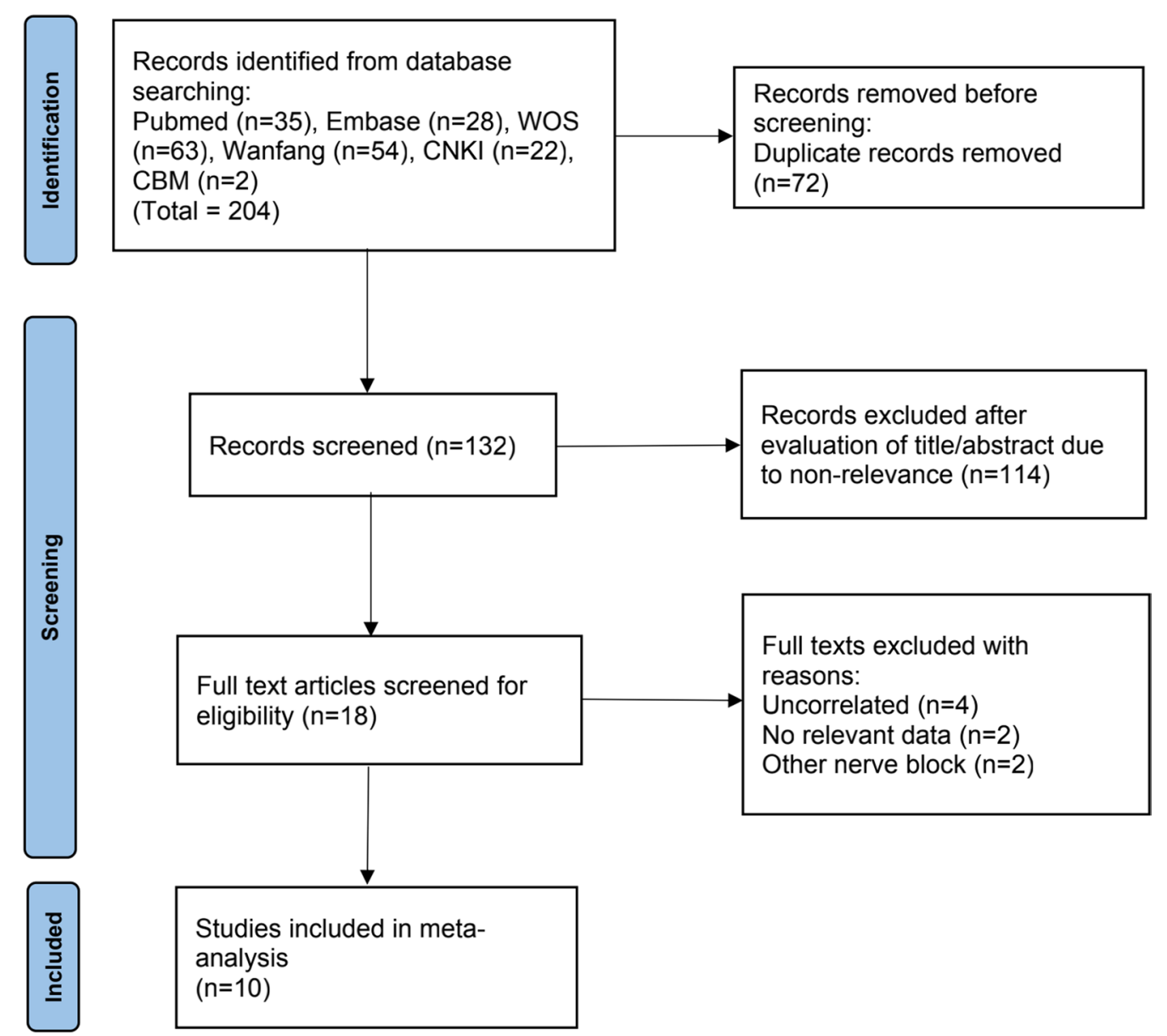

Fig. 1 Flowchart of study selection

85.7 years old and the follow-up period ranged from 1 to 24 months. In most studies lidocaine combined with steroid were used for facet joint block, but Tao et al. used lidocaine alone, $\mathrm{Li}$ et al. used ropivacaine combined with steroid and vitamin B12, and Cheng et al. used lidocaine combined with mecobalamin. According to the Jadad Scale and NOS, nine out of ten included studies were categorized as high-quality studies.

\section{Clinical outcome analysis}

In studies comparing combined therapy with vertebral augmentation, the pooled results showed that combined therapy was associated with significantly lower VAS scores on postoperative day 1 and 7 , month 1 and 3, but there was no significant difference on postoperative month 6 and 12. Similarly, significantly improved ODI scores was observed in combined therapy on postoperative day 1,7 , month 3 , but there was no significant difference on postoperative month 1, 6 and 12 (Table 2). The sensitivity analysis of VAS score at postoperative month 3 and ODI scores at postoperative day 1 and month 3 were demonstrated in Additional file 2: Figure S1, Additional file 3: Figure S2 and Additional file 4: Figure S3.

Regarding studies comparing facet joint block with vertebral augmentation, the pooled results demonstrated a significantly higher VAS score on postoperative month 1 in facet joint block, but there was no significant difference on postoperative day 7, month 3, 6 and 12 (Fig. 2; Table 3). In addition, there was no significant difference in postoperative ODI scores between the two groups during the follow-up (Fig. 3; Table 3).

As for the incidence of refracture, the pooled result showed a significantly lower incidence of refracture in the facet joint block (OR 0.517; 95\% CI0.271-0.986; fixed effect model; $I^{2}$ 9.2\%) (Fig. 4).

\section{Discussion}

Although vertebral augmentation is widely performed in the treatment of OVCF, it is not universally successful. Based on previous literatures, approximately $14-23.6 \%$ 


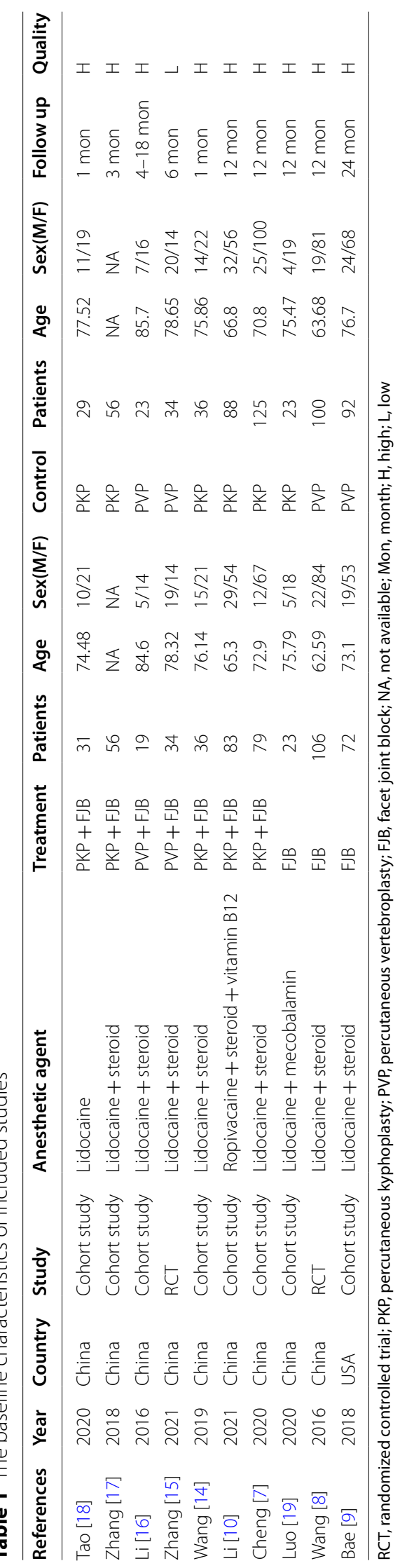


Table 2 The results of combined therapy versus vertebral augmentation

\begin{tabular}{|c|c|c|c|c|c|c|c|}
\hline Variables & Number of studies & Model & WMD & $95 \% \mathrm{Cl}$ & & $I^{2}(\%)$ & $P$ \\
\hline \multicolumn{8}{|l|}{ VAS } \\
\hline 1 day & 7 & Fixed & -1.48 & -1.565 & -1.39 & 0.482 & 0.000 \\
\hline 7 day & 2 & Random & -1 & -1.859 & -0.14 & 0.906 & 0.022 \\
\hline 1 mon & 3 & Random & -0.6 & -0.896 & -0.3 & 0.899 & 0.000 \\
\hline 3 mon & 5 & Random & -0.71 & -0.987 & -0.42 & 0.926 & 0.000 \\
\hline 6 mon & 2 & Random & -0.51 & -1.656 & 0.63 & 0.707 & 0.379 \\
\hline 12 mon & 2 & Random & -0.12 & -0.31 & 0.076 & 0.72 & 0.233 \\
\hline \multicolumn{8}{|l|}{$O D I$} \\
\hline 1 day & 6 & Random & -8.47 & -11.09 & -5.84 & 0.917 & 0.000 \\
\hline 7 day & 3 & Random & -9.97 & -19.45 & -0.49 & 0.995 & 0.039 \\
\hline 1 mon & 3 & Random & -4 & -10.23 & 2.228 & 0.98 & 0.208 \\
\hline 3 mon & 5 & Random & -5.96 & -9.122 & -2.8 & 0.953 & 0.000 \\
\hline 6 mon & 2 & Random & -3.1 & -10.52 & 4.312 & 0.885 & 0.412 \\
\hline 12 mon & 2 & Random & -0.06 & -0.832 & 0.72 & 0.566 & 0.888 \\
\hline
\end{tabular}

VAS, Visual Analogue Scale; ODI, Oswestry Disability Index; Mon, month

of patients suffered from persistent or recurrent pain after vertebral augmentation $[10,20]$. Worse yet, additional interventional procedures were required in about $21-24 \%$ of these patients for pain relief, which brought huge burden on patients and society $[20,21]$. To the best of our knowledge, this is the first meta-analysis investigating the effect of facet joint block to the treatment of OVCF. Our findings suggested the combination of facet joint block and vertebral augmentation could improve the clinical outcomes of patients suffering from OVCF.

Recently the residual pain after vertebral augmentation has attracted the attention of spine surgeons. Some scholars hold the view that residual pain might not be due to a failed operation, but rather to a untreated or a new pain generator [22]. Biomechanical studies showed that secondary kyphotic deformity caused by vertebral fracture could induce subluxation of the posterior structures and increase local stresses, which might be another pain generator $[5,23]$. There was no doubt that pain originating from the posterior structures was unlikely to benefit from vertebral augmentation [5]. Thus, some researchers hypothesized the additional treatment of posterior elements might improve the clinical outcomes of patients with OVCF. In a retrospective study, Wang et al. found significantly lower VAS and ODI scores in the combined therapy group, but this was only observed up to $72 \mathrm{~h}$ postoperatively [14]. In another prospective randomized study, Li et al. reported the additional facet joint block could significantly improve the VAS and ODI scores within the first month after the operation [10]. However, there were some slight differences in Chen et al's study, the results showed the combined therapy could only accelerate the pain relief, the ODI scores did not differ significantly between the two groups [7]. The pooled results of our meta-analysis confirmed that the combined therapy could not only facilitate pain relief within the first 3 months, but also accelerate function recovery up to 7 days postoperatively. Our finding was consistent with a previous study, the anesthetic agents used in the facet joint block could provide approximately 13.26 weeks of pain relief [3]. Thus, the combined therapy is recommended for patients with risk factors associated with posterior pain, such as severe kyphotic deformity and abnormal facet joint signals [6, 24].

Although facet joint block appears to be a useful adjuvant to the treatment of OVCF, it remains controversial whether it can replace vertebral augmentation as a better choice. Wilson et al. indicated only a third of acute OVCF patients technically suitable for PVP could be successfully treated with facet joint block [25]. Im et al. observed approximately half of patients experienced continued pain after facet blocking prior to PVP [24]. In a prospective randomized controlled trial including 206 patients, Wang et al. reported a greater improvement of VAS and ODI scores for patients in the PVP group than those in the facet blocking group [8]. In another study published in Chinese, the authors also found superior analgesic effect and functional recovery in patients receiving PKP at postoperative week 1 and month 1 , when comparing with those receiving facet joint block [19]. On the contrary, Bae et al. demonstrated that both PVP and facet joint block provided significant pain relief for patients with single-level OVCF [9].Our metaanalysis clarified that vertebral augmentation provided better pain relief only at postoperative month 1 , and the 


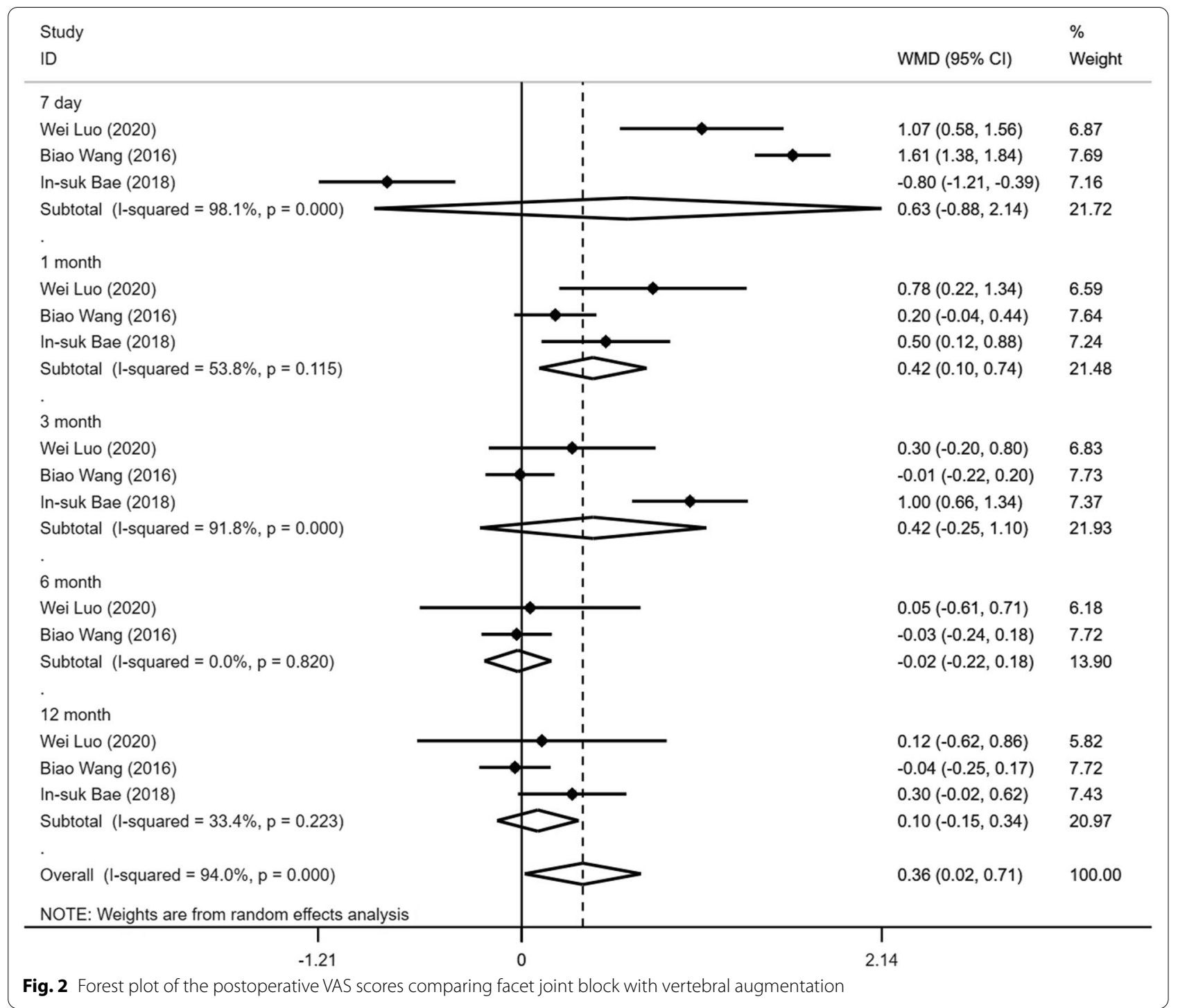

Table 3 The results of facet joint block versus vertebral augmentation

\begin{tabular}{|c|c|c|c|c|c|c|c|}
\hline Variables & Number of studies & Model & WMD & $95 \% \mathrm{Cl}$ & & $I^{2}(\%)$ & $P$ \\
\hline \multicolumn{8}{|l|}{ VAS } \\
\hline 7 day & 3 & Randome & 0.631 & -0.876 & 2.138 & 0.981 & 0.412 \\
\hline 1 mon & 3 & Randome & 0.423 & 0.104 & 0.743 & 0.538 & 0.009 \\
\hline 3 mon & 3 & Randome & 0.425 & -0.248 & 1.098 & 0.918 & 0.215 \\
\hline $6 \mathrm{mon}$ & 2 & Randome & -0.023 & -0.222 & 0.177 & 0 & 0.824 \\
\hline 12 mon & 3 & Randome & 0.066 & -0.106 & 0.238 & 0.334 & 0.454 \\
\hline \multicolumn{8}{|l|}{ ODI } \\
\hline 7 day & 2 & Randome & -1.019 & -18.3 & 16.258 & 0.999 & 0.908 \\
\hline $1 \mathrm{mon}$ & 3 & Randome & 2.073 & -0.648 & 4.795 & 0.96 & 0.135 \\
\hline 3 mon & 3 & Randome & 1.255 & -0.803 & 3.313 & 0.943 & 0.232 \\
\hline 6 mon & 2 & Randome & 0.143 & -0.368 & 0.654 & 0 & 0.583 \\
\hline 12 mon & 3 & Randome & 0.988 & -0.186 & 2.162 & 0.876 & 0.099 \\
\hline
\end{tabular}




\begin{tabular}{|c|c|c|c|}
\hline \multirow{2}{*}{\multicolumn{2}{|c|}{$\begin{array}{l}\text { Study } \\
\text { ID }\end{array}$}} & & \multirow{2}{*}{$\begin{array}{l}\% \\
\text { Weight }\end{array}$} \\
\hline & & WMD $(95 \% \mathrm{Cl})$ & \\
\hline 7 day & \multirow[b]{3}{*}{$\star$} & & \\
\hline Wei Luo (2020) & & $-9.84(-10.89,-8.79)$ & 7.64 \\
\hline Biao Wang (2016) & & $7.79(7.24,8.34)$ & 7.77 \\
\hline Subtotal $(I-$ squared $=99.9 \%, p=0.000)-$ & $\perp$ & \multirow[t]{3}{*}{$-1.02(-18.30,16.26)$} & \multirow[t]{3}{*}{15.41} \\
\hline . & $\frac{1}{1}$ & & \\
\hline 1 month & i & & \\
\hline Wei Luo (2020) & $1 \rightarrow$ & $4.50(3.17,5.83)$ & 7.54 \\
\hline Biao Wang (2016) & 1 & $-0.22(-0.75,0.31)$ & 7.77 \\
\hline In-suk Bae (2018) & & $2.10(1.03,3.17)$ & 7.64 \\
\hline \multirow{2}{*}{ Subtotal $(\mathrm{I}-$ squared $=96.0 \%, \mathrm{p}=0.000$ ) } & & $2.07(-0.65,4.79)$ & 22.95 \\
\hline & $\mathrm{i}$ & & \\
\hline 3 month & 1 & & \\
\hline Wei Luo (2020) & $\rightarrow$ & $1.24(0.29,2.19)$ & 7.67 \\
\hline Biao Wang (2016) & 1 & $-0.45(-1.00,0.10)$ & 7.77 \\
\hline In-suk Bae (2018) & 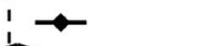 & $3.10(2.01,4.19)$ & 7.63 \\
\hline Subtotal $($ I-squared $=94.3 \%, p=0.000)$ & & $1.26(-0.80,3.31)$ & 23.07 \\
\hline . & $\mathrm{i}$ & & \\
\hline 6 month & i & & \\
\hline Wei Luo (2020) & 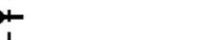 & $0.41(-0.69,1.51)$ & 7.63 \\
\hline Biao Wang (2016) & & $0.07(-0.51,0.65)$ & 7.76 \\
\hline Subtotal $(I-$ squared $=0.0 \%, p=0.592)$ & 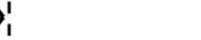 & $0.14(-0.37,0.65)$ & 15.39 \\
\hline . & i & & \\
\hline & 1 & & \\
\hline Wei Luo (2020) & $\frac{1}{1}$ & $0.56(-0.25,1.37)$ & 7.71 \\
\hline Biao Wang (2016) & 1 & $0.23(-0.25,0.71)$ & 7.78 \\
\hline In-suk Bae (2018) & - & $2.30(1.41,3.19)$ & 7.69 \\
\hline Subtotal $(1-$ squared $=87.6 \%, p=0.000)$ & & $0.99(-0.19,2.16)$ & 23.18 \\
\hline \multicolumn{4}{|l|}{. } \\
\hline Overall $(I-s q u a r e d=98.9 \%, p=0.000)$ & & $0.91(-1.05,2.86)$ & 100.00 \\
\hline \multicolumn{2}{|l|}{ NOTE: Weights are from random effects analysis } & & \\
\hline$T$ & & $T$ & \\
\hline-18.3 & & 16.3 & \\
\hline
\end{tabular}

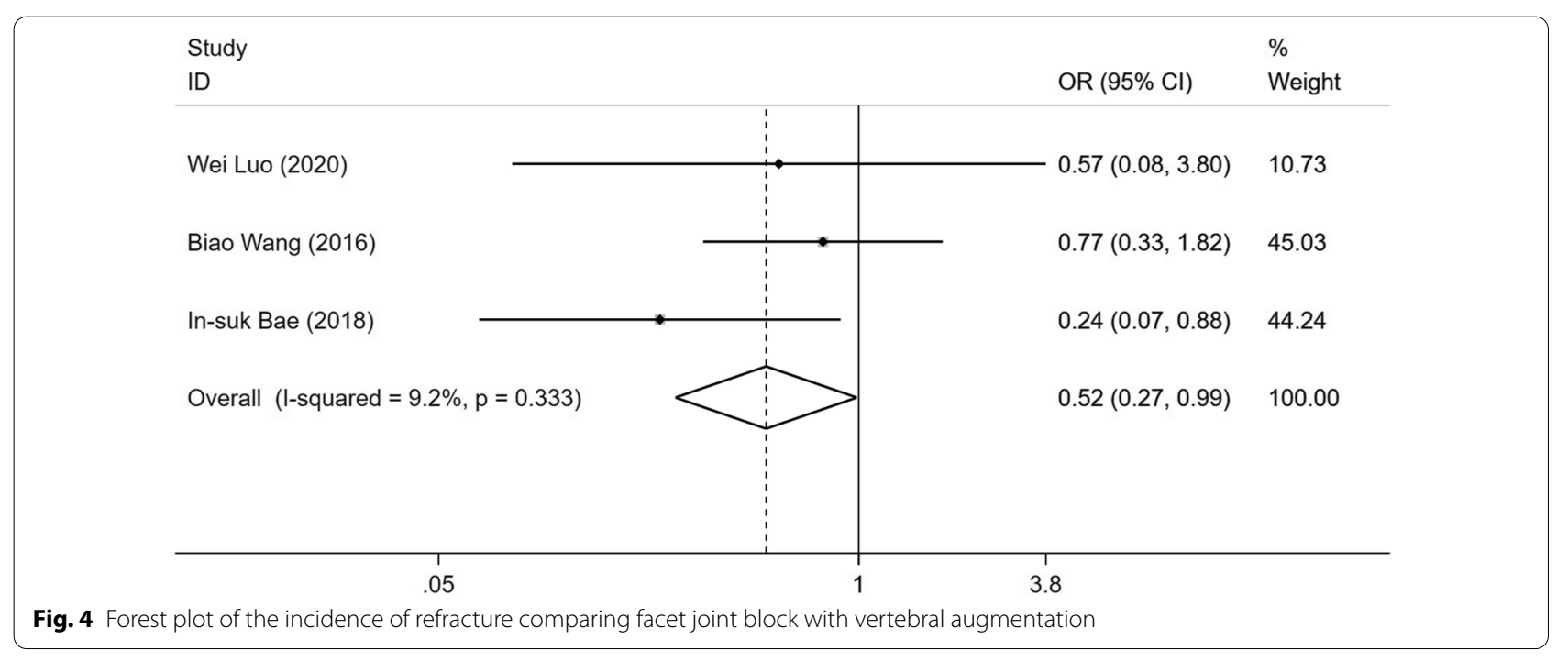


difference in the improvement of ODI scores between the two procedures was insignificant.

In the literature, the incidence of refracture after vertebral augmentation ranged from 2 to $52 \%$ [26, 27], which was a serious complication that urgently needs to be solved. Although several studies have been conducted to find an effective alternative, the results were debatable. While Luo et al. reported no significant difference in the occurrence of refracture between facet blocking and PKP groups [19]. Wang et al. found a slightly higher rate of refracture in the PVP group [8]. In another study, Bae et al. showed that there was a significantly higher incidence of refracture in the PVP group compared with facet blocking group [9]. Based on the limited published studies, our meta-analysis indicated that vertebral augmentation was associated with higher refracture risk comparing with facet joint block. It is likely that cement augmentation increases the strength and stiffness of the fractured vertebrae, resulting in greater stress on the adjacent vertebrae and subsequently higher risk of refracture [28].

\section{Limitation}

There were some limitations in our study. Firstly, the number of eligible studies was limited and most studies were retrospective in nature. Secondly, the sample size was relatively small, which prevented us from drawing a stronger conclusion. Thirdly, the anesthetic agents and cement augmentation techniques in the various studies were not completely consistent, which might influence the outcomes.

\section{Conclusion}

Current evidence suggested that facet joint block might be considered as a complementary to vertebral augmentation in the treatment of OVCF, especially for patients with risk factors associated with posterior pain. However, the facet joint block alone could not be used as an effective alternative to vertebral augmentation.

\begin{abstract}
Abbreviations
OVCF: Osteoporotic vertebral compression fractures; PVP: Percutaneous vertebroplasty; PKP: Percutaneous kyphoplasty; PRISMA: Preferred reporting items for systematic reviews and meta-analyses; WOS: Web of science; CNKI: China National Knowledge Infrastructure; CBM: Chinese BioMedical Literature Database; VAS: Visual Analogue Scale; ODI: Oswestry Disability Index; RCT: Randomized controlled trial; NOS: Newcastle-Ottawa Scale.
\end{abstract}

\section{Supplementary Information}

The online version contains supplementary material available at https://doi. org/10.1186/s13018-022-02933-9.

Additional file 1. The PRISMA checklist.
Additional file 2: Figure S1. Sensitivity analysis of VAS score at postoperative month 3 .

Additional file 3: Figure S2. Sensitivity analysis of ODI score at postoperative day 1.

Additional file 4: Figure S3. Sensitivity analysis of ODI score at postoperative month 3 .

\section{Acknowledgments}

Not applicable.

\section{Authors' contributions}

ZC conceived the review and draft the manuscript. CS, JC and JS collected the data and conducted analyses. WLu revised the manuscript. All authors approved the final manuscript. All authors read and approved the final manuscript.

Funding

There is no funding information to declare.

\section{Availability of data and materials}

The data are available from the corresponding author on reasonable request.

\section{Code availability}

Not applicable.

\section{Declarations}

Ethics approval and consent to participate

Not applicable.

\section{Consent for publication}

Not applicable.

\section{Competing interests}

The authors declare no conflicts of interest.

\section{Author details}

${ }^{1}$ Department of Orthopedics Surgery, Fujian Medical University Union Hospital, Fuzhou 350001, Fujian, China. ${ }^{2}$ Department of Orthopedics Surgery, The First People's Hospital of Yulin, Yulin 537000, Guangxi, China. ${ }^{3}$ Department of Emergency, Zhaotong Traditional Chinese Medicine Hospital, Zhaotong 657000, Yunnan, China.

Received: 23 November 2021 Accepted: 10 January 2022

Published online: 21 January 2022

\section{References}

1. Yoo CM, Park KB, Hwang SH, Kang DH, Jung JM, Park IS. The analysis of patterns and risk factors of newly developed vertebral compression fractures after percutaneous vertebroplasty. J Korean Neurosurg Soc. 2012;52:339-45. https://doi.org/10.3340/jkns.2012.52.4.339.

2. Yu W, Xu W, Jiang X, Liang D, Jian W. Risk factors for recollapse of the augmented vertebrae after percutaneous vertebral augmentation: a systematic review and meta-analysis. World Neurosurg. 2018;111:119-29. https://doi.org/10.1016/j.wneu.2017.12.019.

3. Park KD, Jee H, Nam HS, Cho SK, Kim HS, Park Y, Lim OK. Effect of medial branch block in chronic facet joint pain for osteoporotic compression fracture: one year retrospective study. Ann Rehabil Med. 2013;37:191201. https://doi.org/10.5535/arm.2013.37.2.191.

4. Doi T, Akai M, Endo N, Fujino K, Iwaya T. Dynamic change and influence of osteoporotic back pain with vertebral fracture on related activities and social participation: evaluating reliability and validity of a newly developed outcome measure. J Bone Miner Metab. 2013;31:663-73. https:// doi.org/10.1007/s00774-013-0458-5. 
5. Bogduk N, MacVicar J, Borowczyk J. The pain of vertebral compression fractures can arise in the posterior elements. Pain Med (Malden, Mass) 2010;11:1666-73. https://doi.org/10.1111/j.1526-4637.2010.00963.x.

6. Lehman VT, Wood CP, Hunt CH, Carter RE, Allred JB, Diehn FE, Morris JM, Wald JT, Thielen KR. Facet joint signal change on MRI at levels of acute/subacute lumbar compression fractures. AJNR Am J Neuroradiol. 2013:34:1468-73. https://doi.org/10.3174/ajnr.A3449.

7. Cheng Y, Wu X, Shi J, Jiang H. Percutaneous vertebroplasty and facet blocking for treating back pain caused by osteoporotic vertebral compression fracture. Pain Res Manage. 2020;2020:5825317. https://doi.org/ 10.1155/2020/5825317.

8. Wang B, Guo H, Yuan L, Huang D, Zhang H, Hao D. A prospective randomized controlled study comparing the pain relief in patients with osteoporotic vertebral compression fractures with the use of vertebroplasty or facet blocking. Eur Spine J Off Publ Eur Spine Soc Eur Spinal Deformity Soc Eur Sect Cerv Spine Res Soc. 2016;25:3486-94. https://doi. org/10.1007/s00586-016-4425-4.

9. Bae IS, Chun HJ, Bak KH, Yi HJ, Choi KS, Kim KD. Medial branch block versus vertebroplasty for 1-level osteoporotic vertebral compression fracture: 2-year retrospective study. World Neurosurg. 2019;122:e1599-605. https://doi.org/10.1016/j.wneu.2018.11.142.

10. Li QD, Yang JS, Gong HL, Wei JM, Wang XF, Zou P, Zhang B, Hao DJ, Zhao YT, Chu L. Can additional facet joint block improve the clinical outcome of kyphoplasty for acute osteoporotic vertebral compression fractures? Pain Phys. 2021;24:283-91.

11. Moher D, Liberati A, Tetzlaff J, Altman DG. Preferred reporting items for systematic reviews and meta-analyses: the PRISMA statement. BMJ (Clin Res ed). 2009;339:b2535. https://doi.org/10.1136/bmj.b2535.

12. Jadad AR, Moore RA, Carroll D, Jenkinson C, Reynolds DJ, Gavaghan DJ, McQuay HJ. Assessing the quality of reports of randomized clinical trials: Is blinding necessary? Control Clin Trials. 1996;17:1-12. https://doi.org/10. 1016/0197-2456(95)00134-4.

13. Stang A. Critical evaluation of the Newcastle-Ottawa scale for the assessment of the quality of nonrandomized studies in meta-analyses. Eur J Epidemiol. 2010;25:603-5. https://doi.org/10.1007/s10654-010-9491-z.

14. Wang L, Cheng J, Yan Z, Zhou Y, Wu Y. Clinical efficacy of percutaneous kyphoplasty combined with facet joint blocking in treatement of single-segment vertebral compression fractures. J Reg Anat Oper Surg. 2019;28:465-9. https://doi.org/10.11659/jjssx.03E019184.

15. Zhang Y, Zheng F. Clinical observation of unilateral percutaneous vertebroplasty combined with facet blocking in elderly patients with osteoporotic thoracolumbar fractures. Contemp Med. 2021;27:87-9. https://doi.org/10.3969/j.issn.1009-4393.2021.16.032.

16. Li X, ZhaoZhang ZY, Yang $H$. The early efficacy of unilateral percutaneous vertebroplasty combined with facet blocking in elderly patients with osteoporotic thoracolumbar fractures. Chin J Bone Joint Inj. 2016;31:7467. https://doi.org/10.7531/j.issn.1672-9935.2016.07.027.

17. Zhang B, Zou X, Zhang Y, Hu Z, Chang P. The efficacy of PKP combined with medial branch block in the treatment of osteoporotic vertebral compression fracture. J Pract Orthop. 2018;24:927-30.

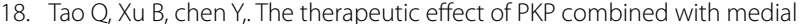
branch block on osteoporotic vertebral compression fracture. Zhejiang J Integr Tradit Chin West Med. 2020;30:676-8. https://doi.org/10.3969/j.issn. 1005-4561.2020.08.022.

19. Luo W, Cheng J, Sun Q, Chen C, Li H, Ma C, Su R, Feng X, Sun Y. Facet joint injection versus percutaneous kyphoplasty for mild vertebral fragility fracture: rapid analgesia and restoration of spinal stability. Chin J Tissue Eng Res. 2020;24:3168-73. https://doi.org/10.3969/j.issn.2095-4344.2609.

20. Georgy BA. Interventional techniques in managing persistent pain after vertebral augmentation procedures: a retrospective evaluation. Pain Phys. 2007;10:673-6.

21. Hatgis J, Granville M, Jacobson RE. Evaluation and interventional management of pain after vertebral augmentation procedures. Cureus. 2017;9:e1061. https://doi.org/10.7759/cureus.1061.

22. Kamalian S, Bordia R, Ortiz AO. Post-vertebral augmentation back pain: evaluation and management. AJNR Am J Neuroradiol. 2012;33:370-5. https://doi.org/10.3174/ajnr.A2775.

23. Mitra R, Do H, Alamin T, Cheng I. Facet pain in thoracic compression fractures. Pain Med (Malden, Mass). 2010;11:1674-7. https://doi.org/10. 1111/j.1526-4637.2010.00953.x.
24. Im TS, Lee JW, Lee E, Kang Y, Ahn JM, Kang HS. Effects of facet joint injection reducing the need for percutaneous vertebroplasty in vertebral compression fractures. Cardiovasc Intervent Radiol. 2016;39:740-5. https://doi.org/10.1007/s00270-015-1286-X.

25. Wilson DJ, Owen S, Corkill RA. Facet joint injections as a means of reducing the need for vertebroplasty in insufficiency fractures of the spine. Eur Radiol. 2011;21:1772-8. https://doi.org/10.1007/s00330-011-2115-5.

26. Grados F, Depriester C, Cayrolle G, Hardy N, Deramond H, Fardellone P. Long-term observations of vertebral osteoporotic fractures treated by percutaneous vertebroplasty. Rheumatology (Oxford). 2000;39:1410-4. https://doi.org/10.1093/rheumatology/39.12.1410.

27. Kim MH, Lee AS, Min SH, Yoon SH. Risk factors of new compression fractures in adjacent vertebrae after percutaneous vertebroplasty. Asian Spine J. 2011;5:180-7. https://doi.org/10.4184/asj.2011.5.3.180.

28. Belkoff SM, Mathis JM, Jasper LE, Deramond H. The biomechanics of vertebroplasty. The effect of cement volume on mechanical behavior. Spine. 2001;26:1537-41. https://doi.org/10.1097/00007632-200107150-00007.

\section{Publisher's Note}

Springer Nature remains neutral with regard to jurisdictional claims in published maps and institutional affiliations.

Ready to submit your research? Choose BMC and benefit from

- fast, convenient online submission

- thorough peer review by experienced researchers in your field

- rapid publication on acceptance

- support for research data, including large and complex data types

- gold Open Access which fosters wider collaboration and increased citations

- maximum visibility for your research: over $100 \mathrm{M}$ website views per year

At BMC, research is always in progress.

Learn more biomedcentral.com/submissions 